\title{
Distribution Network Optimization Based on Genetic Algorithm
}

\author{
Ramadoni Syahputra \\ Department of Electrical Engineering, Faculty of Engineering \\ Universitas Muhammadiyah Yogyakarta \\ Kampus Terpadu UMY, Jl. Lingkar Selatan, Kasihan, Bantul, Yogyakarta 55183 \\ E-mail: ramadoni@umy.ac.id
}

\begin{abstract}
This paper presents a new robust optimization technique for distribution network configuration, which can be regarded as a modification of the recently developed genetic algorithm. The multi-objective genetic algorithm has been applied to this problem to optimize the total cost while simultaneously minimize the power loss and maximize the voltage profile. The IEEE 69-bus distribution network is used in the tests, and test results have shown that the algorithm can determine the set of optimal nondominated solutions. It allows the utility to obtain the optimal configuration of the network to achieve the best system with the lowest cost. Copyright $($ ) 2017 Universitas Muhammadiyah Yogyakarta- All rights reserved.
\end{abstract}

Keywords: Distribution network, Optimization, Network Reconfiguration, Genetic Algorithm, Multi-objective

\section{Introduction}

Electric power distribution networks are an important component in the electric power system. Distribution networks are usually radially configured for effective coordination of their protective devices [1]-[3]. In its operations, there are two types of switches used in distribution networks. These switches are generally used for protection and configuration management purposes [4]-[5]. Both switches are sectionalizing switches (switches that are normally closed) and tie switches (switches that are normally opened) [6]-[8]. By changing the status of the division and binding switch, the distribution system configuration varies and the load is transferred between feeders while the radial configuration format of the power supply is still maintained and all loading points are not interrupted. This activity is defined as a distribution feeder reconfiguration. The advantage of reconfiguring feeders is the reduction in real power loss, balancing system load, improving system security and reliability, increasing bus voltage profiles, and improving power quality [9]-[11].

In the most recent development, the distribution network has been injected by many small-scale

Manuscript received February 2017, revised March 2017 generators, known as distributed generators (DG) [12]-[16]. Small-scale generators are generally sourced from renewable energy. Distributed generators are units of electricity generators that are connected to the network or stand alone located within the distribution system at or near the end user [17]. The latest developments in DG technologies such as sun, wind, fuel cells, hydrogen, and biomass have attracted attention for utilities to accommodate DG units in their systems [18]-[21]. The introduction of DG units brings a number of technical problems to the system because distribution networks with DG units are no longer passive [22].

Practical aspects of the electric power distribution system must also be considered for the reconfiguration of the feeder. Actual distribution suppliers are mainly unbalanced in nature for a variety of reasons, namely, the presence of single, double, and three-phase line sections, unbalanced consumer loads and the existence of asymmetrical line sections [23]-[27]. The inclusion of system imbalances increases the dimensions of feeder configuration problems because all three phases must be considered instead of a balanced representation of single phases [28]-[30]. As a result, distribution system analysis certainly 
requires a power flow algorithm with a complete three-phase model [31]-[32].

This paper proposes the use of genetic algorithm techniques for reconfiguring feeder suppliers to improve distribution network performance with the presence of distributed generators. The two objectives that must be minimized are real power losses and the number of transfer operations from the tie switch and division, while all feeders keep balancing the load. The effectiveness of methodology is examined by the 69 buses IEEE distribution system standard.

\section{Distribution Network Optimization}

A very effective way to optimize distribution networks is to reconfigure the network. How to reconfigure this network is relatively inexpensive compared to reconfiguration of distribution networks is a very important operation and can be used to reduce loss of distribution feeders and improve system security. Configuration can vary through switching operations to transfer loads between feeders. Two types of switches are used: switches are usually closed (switch sectionalizing) and switches are usually open (switch switches) [8]. By changing the feeder open / close status, switching the load current can be transferred from the feeder to the feeder. During errors, switches are used for fault isolation and service recovery. There are many numbers of switches in the distribution system, and the number of possible switching operations is extraordinary. Feeder reconfiguration thus becomes a complicated decision-making process to be followed by operator officers. There are a number of switches that are closed and usually open in the distribution system. The number of possible transfer actions makes reconfiguring feeders into complicated decision making for system operators. Figure 1 shows a schematic diagram of a simplified main circuit of a distribution system. In the figure, CB1-CB6 is a normally closed switch that connects a line section, and CB7 is a normally open switch that connects two main feeders. Both substations can be connected by CB8, while CB9, when closed, will make a loop.

Distribution system operations can be achieved optimally through reconfiguring the system to minimize losses due to changes in operating conditions. The reconfiguration problem basically belongs to a combinatorial optimization problem because this problem is done by considering various operational constraints in a large-scale distribution system. Therefore, it is difficult to quickly get the optimal solution that is right on the real system. The flowchart for the feeder reconfiguration algorithm is shown in Figure 2.

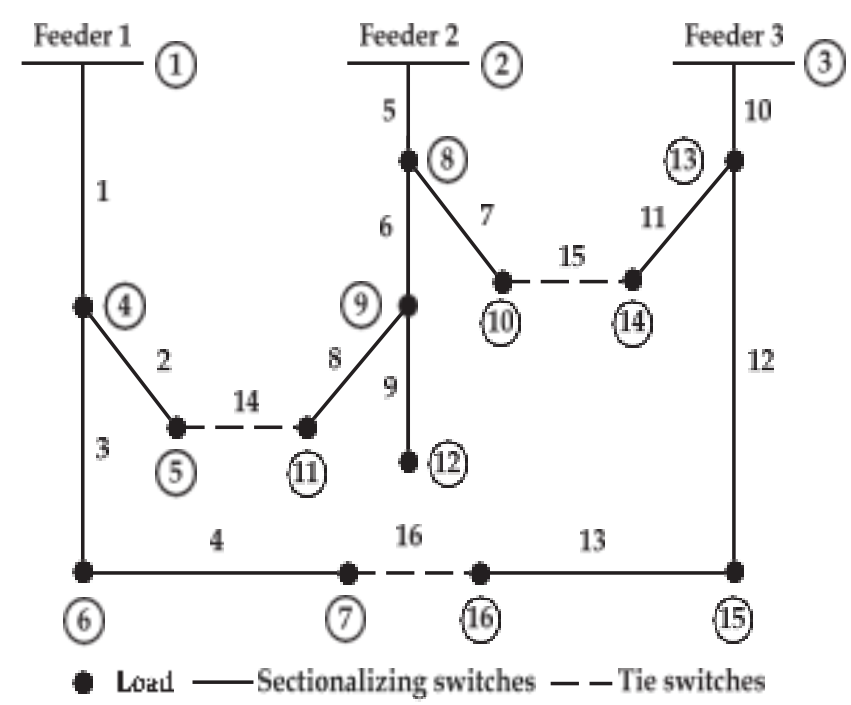

Fig. 1. Schematic diagram of a distribution system for reconfiguration

The study of power flow is an important tool for steady state power system operational analysis. The main target of the power flow analysis is to calculate the flow of real and reactive forces in each row as well as the magnitude and phase angle of stress on each bus from the system for specific loading conditions [4]. When the power distribution network becomes increasingly complex, there is a higher demand for efficient and reliable system operation. As a result, power flow studies must have the ability to handle a variety of system configurations with sufficient accuracy and speed.

The electric power system is generally in steady state analysis operated with balanced three-phase generation and load by transposing the transmission line. In radial distribution systems it does not apply, so the model based on single-phase analysis is not enough to represent an unbalanced three-phase network. The method used as the main tool to solve the problem of unbalanced power flow is based on the number of actual phases with all relevant equipment modeled in phase coordinates. Thus special treatment is needed for the power flow solution to complete the network. 


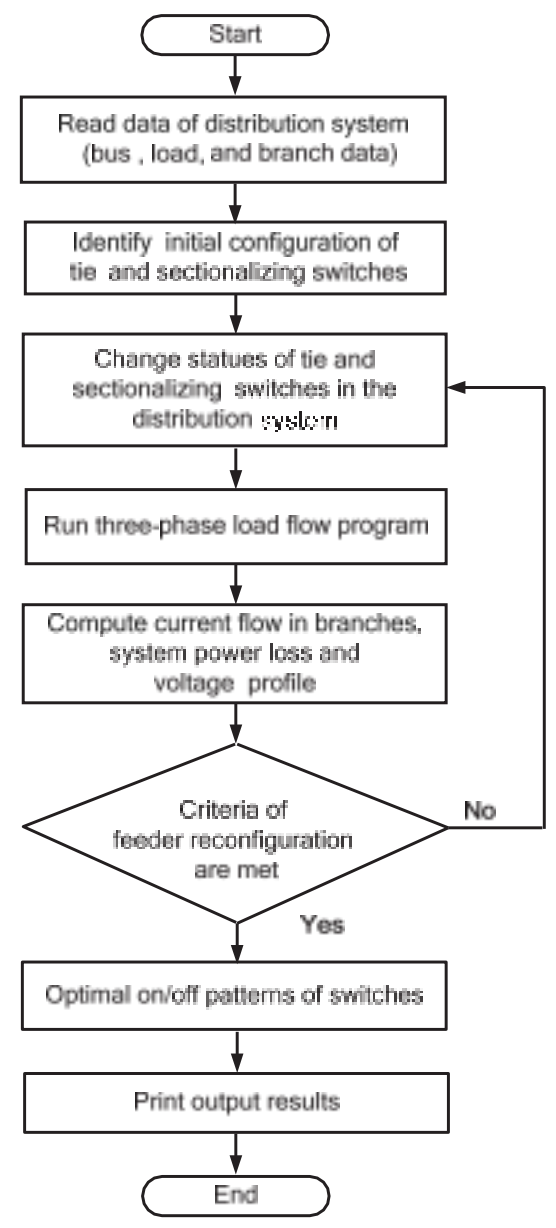

Fig. 2. Flowchart of distribution network reconfiguration

In a distribution network, equivalent circuits can also be expressed in nominal terms. This form is similar to a medium distance transmission network. The nominal pi network model is considered very representative and facilitates network analysis, especially for reconfiguration purposes. In this pi equivalent model, channel capacitance is evenly distributed along the line. The series component of this circuit is in the form of an array of resistance and inductance that are connected in series in the network. Furthermore, the series impedance and shunt capacitance for the three-phase line are $3 \times 3$ complex matrices, where this component also takes into account the joint inductive coupling between phases.

\section{Genetic Algorithm}

In genetic algorithms, chromosomes (input variables) produce a set of output function variable costs. This cost function can be a mathematical function. The goal is to modify the output in several desired modes by finding the value that is appropriate for the input variable. As an illustration is when filling the bath with water. In this case, the cost is the difference between the desired and actual water temperature. The input variable is how many hot and cold spigots change. In this case the cost function is the experimental result of gripping your hand in the water. So we see that determining the appropriate cost function and deciding which variables to use are closely related. The term fitness is widely used to determine the output of objective functions in the GA literature. Fitness implies a problem of maximization. Although fitness has a closer relationship with biology than term costs, we have adopted term costs, because most of the optimization literature relates to minimization, then costs. They are equal.

GA starts by defining chromosomes or array values of the optimization variables. If the chromosome has the Nvar variable, the Nvardimensional optimization problem, given by 1 , $\mathrm{p} 2, \ldots, \mathrm{pNvar}$, then the chromosome is expressed as the row vector of the Nvar element.

$$
\text { chromosome }=[p 1, p 2, p 3, \ldots, p N \text { var }]
$$

For example, finding the maximum height on a topographic map requires a cost function with input variables of longitude (x) and latitude (y)

$$
\text { chromosome }=[\mathrm{x}, \mathrm{y}]
$$

where Nvar $=2$. Each chromosome has a cost found by evaluating the cost func- tion, $\mathrm{f}$, at $\mathrm{p} 1, \mathrm{p} 2, \ldots$, pNvar:

$$
\text { cost }=f(\text { chromosome })=f(p 1, p 2, \ldots, p N v a r)(3)
$$

Because we tried to find a peak in a park, the cost function was written as negative from a height to put it in the form of a minimization algorithm that is

$$
f(x, y)=- \text { elevation at }(x, y)
$$

In many cases, the cost function is very difficult as in the case of maximizing the car's gas mileage. The user must decide which variable is the most important problem. In this case the variables are numerous. Consequently the GA process can cause traffic jams. The variables used to optimize gas mileage may include car size, engine size, and material weight. Other variables such as paint color and type of headlights do not significantly affect 
the distance of the car, so it does not need to be included in the algorithm. Sometimes the correct number and choice of variables come from experience or running optimization experiments. At other times we have an analytical cost function, which is determined by

$$
f(w, x, y, z)=2 x+3 y+z / 100000+\sqrt{ } 9876
$$

In this case all variables are located between 1 and 10, which can be simplified in order to help the optimization algorithm. Because the terms $\mathrm{w}$ and $\mathrm{z}$ are very small in areas of interest, they can be disposed of for most purposes. Thus the fourdimensional cost function is sufficiently modeled with two variables in the area of interest.

In most optimization problems, it requires variable restrictions or restrictions. Allowing the weight of the car to reach zero or allowing the width of the car to be 10 meters is an impractical variable value. Restricted variables come from three brands, while unrestricted variables can take any value. Hard limits in the form $>,<, \geq$, and $£$ can be imposed on variables. If the variable has exceeded the limit then it is set equal to that bound. If $\mathrm{x}$ has a limit of $0 £ \mathrm{x} £ 10$, and the algorithm sets $\mathrm{x}=11$, then $\mathrm{x}$ will be set back to 10 . Then the variable can be converted into a new variable that is inherently an obstacle. If $\mathrm{x}$ has a limit of $0 £ \mathrm{x} £ 10$, then $\mathrm{x}=5 \sin \mathrm{y}+5$ is a transformation between a limited variable $\mathrm{x}$ and an infinite variable $\mathrm{y}$. Varying $\mathrm{y}$ for any value is the same as varying $\mathrm{x}$ within its limits. This type of transformation transforms a limited optimization problem into an unrestricted optimization problem in a smooth way. Finally there may be a limited number of value variables to choose from, and all values are in the desired region. Such problems come in the form of choosing a part of limited inventory.

The dependent variable will represent a specific problem for the optimization method because varying one variable also changes the value of the other variable. For example, the size and weight of the car depends. Increasing the size of the car is likely to increase weight too, except for a few other factors such as the type of material that also changes. Independent variables, such as the Fourier series coefficients, do not interact with each other. If 5 coefficients are not enough to represent the function, more can be added without having to recalculate the original 5.

GA operation begins with a group of chromosomes called the population. The population has an Npop chromosome and is a Npop matrix $¥$ Nbits which is filled with random and zero generated using the expression blow

$$
\text { pop=round(rand(Npop, Nbits)); }
$$

where function (Npop, Nbits) produces Npop matrix $¥$ Nbits uniform random numbers between zero and one. The function round rounds the number to the closest integer which in this case is 0 or 1 . Each row in the matrix examined is a chromosome.

Table 1. Initial Population of 8 Random Chromosomes and the Corresponding Cost

\begin{tabular}{ll}
\hline Chromosome & Cost \\
\hline 00101111000110 & -12359 \\
11100101100100 & -11872 \\
00110010001100 & -13477 \\
00101111001000 & -12363 \\
11001111111011 & -11631 \\
01000101111011 & -12097 \\
11101100000001 & -12588 \\
01001101110011 & -11860 \\
\hline
\end{tabular}

Chromosomes correspond to different longitude and latitude. Then the variable is passed to the cost function for evaluation. Table 1 shows an example of the initial population and their costs for Npop $=8$ random chromosomes. Chromosome location is shown in a topographic map as shown in Figure 3. 


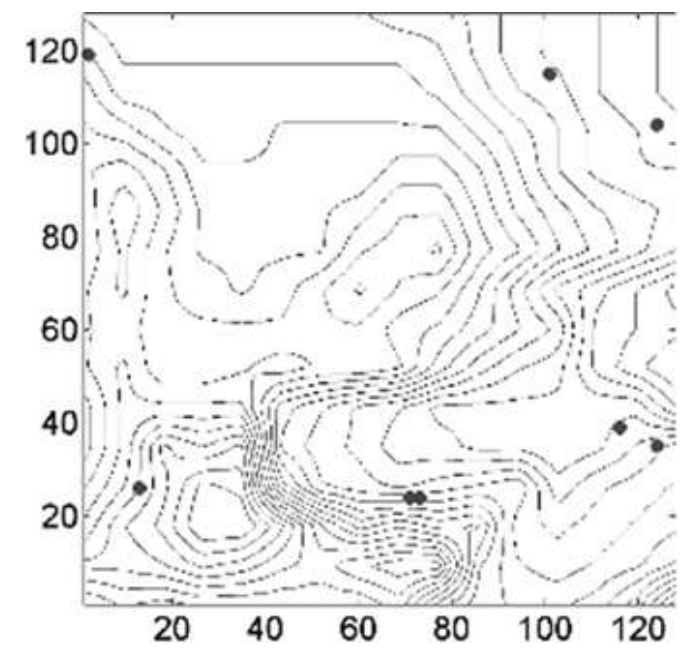

Fig. 3. A topographic map of the cost surface with the 8 initial population members indicated by large dots

In GA techniques, a random mutation process will change a certain percentage of the bits in the chromosome list. This mutation is the second way GA explores the cost surface. This can introduce features not in the original population and make the GA not connected too quickly before sampling the entire surface of the cost. One point mutation changes 1 to 0 , and vice versa. The points of the mutation are chosen randomly from Npop $¥$ Nbits a number of bits in the population matrix. The increasing number of mutations increases the freedom of the algorithm to search outside the current space variable area. This also tends to divert the algorithm's attention from converging to popular solutions. Mutations do not occur in the last iteration.

After mutations occur, the costs associated with the offspring and mutated chromosomes are calculated. The process described is repeated.

The number of generators that develop depends on whether an acceptable solution is reached or the number of iterations specified is exceeded. After a while all chromosomes and related costs will be the same if not for mutations. At this point the algorithm must be stopped.

Most GPS track population statistics in the form of population mean and minimum cost. In this issue after three generations the global minimum was found to be -14199 .

\section{Results and Discussion}

In this research, there has been a reconfiguration of the distribution network with a test system for case studies, namely a radial distribution system that has 69 buses, 7 laterals and 5 tie-lines, as shown in Figure 1. Current carrying capacity of the No.1-9 branch is 400 amperes, 46-49 and No. 52-64 is 300 amperes and the remaining other branches including the tie line are 200 amperes.

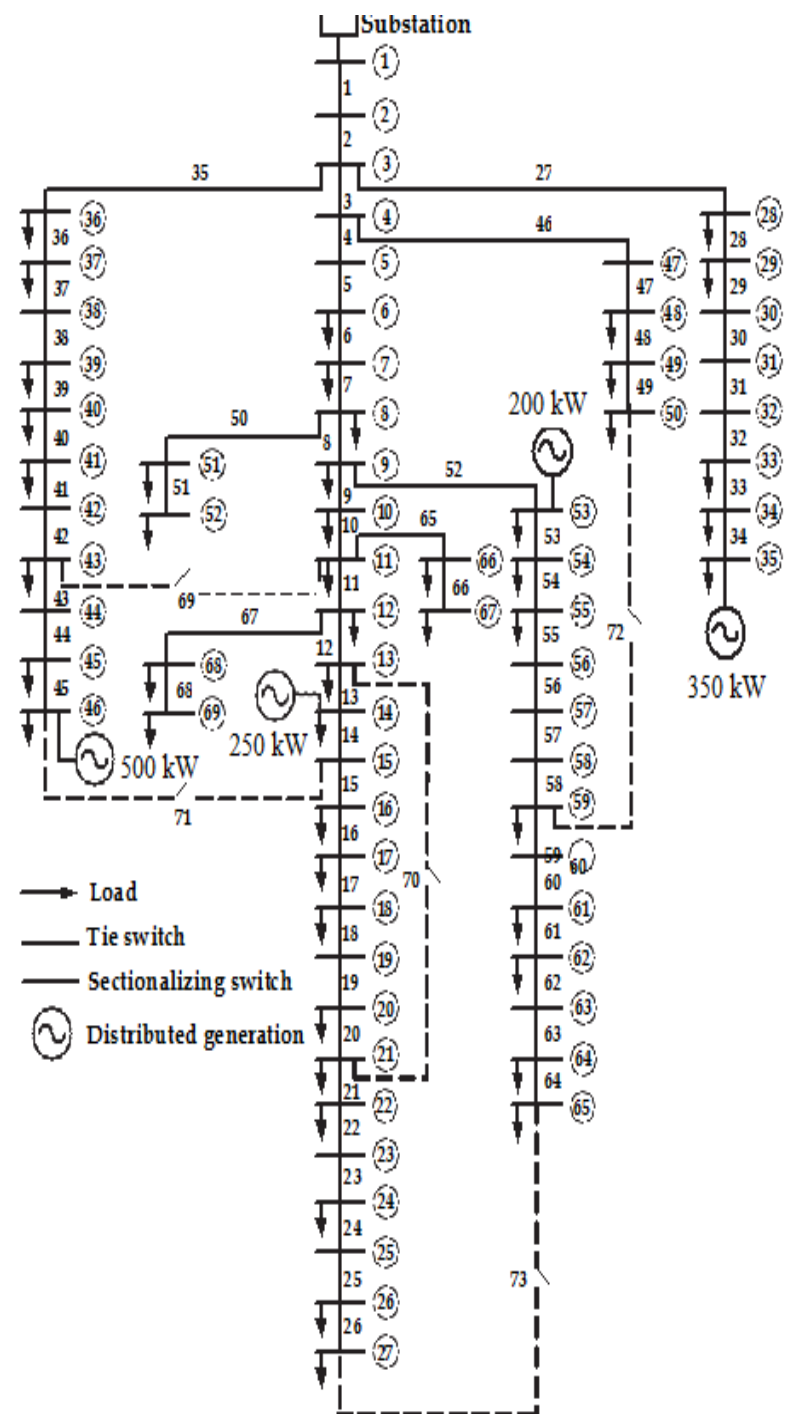

Fig. 4. The IEEE 69-bus distribution network

Furthermore, the distribution network modeled four DG units installed on buses 14, 35, 46 and 53 with capacities of $300,200,100$, and $400 \mathrm{~kW}$, respectively. The basic values for voltage and power are $12.66 \mathrm{kV}$ and $100 \mathrm{MVA}$. Each branch in the system has a division switch for reconfiguration purposes. Load data is given in Table 1 and Table 2 
provides branch data [8]. The initial status of all sectionalize switches (switches No. 1-68) is closed while all tie-switches (switches No. 69-73) are open. The total load for this test system is $3,801.89$ $\mathrm{kW}$ and 2,694.10 kVAr. The minimum and maximum voltages are set at 0.95 and 1.05 p.u. In this study network reconfiguration was carried out using genetic algorithm based optimization methods. This algorithm is a popular algorithm in optimization techniques.

The results of network reconfiguration research are summarized in Table 2. In cases 1-5 (balanced system), system power losses and LBI are highest, and the minimum bus voltage in the system violates the lower limit of 0.95 per unit. The voltage of the reconfiguration is relatively better on each bus compared to before reconfiguration. The reconfiguration shows that the voltage on buses 57 65 is below 0.95 p.u. because a large load of 1,244 $\mathrm{kW}$ is taken on bus 61 . Before the addition of four DG units, the system power losses are $673.89 \mathrm{~kW}$. This fact confirms that DG units can usually, though not necessarily, help reduce the flow of current in the feeder and therefore contribute to a reduction in power losses, especially because they are usually placed near the load supplied. In cases 2 to 5 , where the feeder is reconfigured and the voltage constraints are imposed in the optimization process, no bus voltage is violated.

The results show that the minimum system power loss in case 2, the LBI index is minimal in case 3, and the number of switch switching operations is minimal in case 4 , as expected before. This fact is clearly seen from case 5 that genetic algorithms offer some flexibility that can be utilized for additional trade-offs between increasing an objective function and degrading others. This flexibility is still in tolerance and does not interfere with system performance. The power loss in case 5 is slightly higher than in case 2 but case 5 only requires 6 , not 8 , switching operations. Although LBI case 3 is better than case 5 , it loses power and the number of switching operations 3 cases is greater. When compared with case 4 with case 5, a power loss of about $18 \mathrm{~kW}$ can be saved from two switching operations again. The distribution network model with genetic algorithm-based optimization has the potential to solve decisionmaking problems in feeder reconfiguration and offer decision makers some flexibility to combine their own assessments and priorities in the optimization model.

The chromosome of case 5 for lost power is 0.961, for load balancing index is 0.697 and for the number of switching operations is 0.666 . When the system's unbalanced loading is $20 \%$ in case 6 , the power loss before the feeder reconfiguration is around $624,962 \mathrm{~kW}$. The case 6 membership value for power loss is 0.840 , for the 0.129 load balancing index and for the number of switching operations is 0.666 .

Table 2. Results of case study

\begin{tabular}{|c|c|c|c|c|c|c|}
\hline & Case 1 & Case 2 & Case 3 & Case 4 & Case 5 & Case 6 \\
\hline Sectionalizing switches to be open & - & $\begin{array}{c}12,20, \\
52,61\end{array}$ & $\begin{array}{c}42,14, \\
20,52,61\end{array}$ & 52,62 & $13,52,63$ & 12,5261 \\
\hline Tie switches to be closed & - & $\begin{array}{c}70,71, \\
72,73\end{array}$ & $\begin{array}{c}69,70, \\
71,72,73\end{array}$ & 72,73 & $71,72,73$ & $71,72,73$ \\
\hline Power loss (kW) & 586.83 & 246.33 & 270.81 & 302.37 & 248.40 & 290.98 \\
\hline Minimum voltage (p.u.) & 0.914 & 0.954 & 0.954 & 0.953 & 0.953 & 0.965 \\
\hline $\begin{array}{c}\text { Load balancing index (LBI) } \\
\text { Number of switching } \\
\text { operations }\end{array}$ & 2.365 & 1.801 & 1.748 & 1.921 & 1.870 & 2.273 \\
\hline
\end{tabular}




\section{Conclusion}

In this study an approach has been presented to reconfigure and install DG units simultaneously in a distribution system. Distribution network power loss reduction method (only network reconfiguration, only DG installation, DG installation after reconfiguration) is also simulated to determine the advantages of the proposed method. Genetic algorithm-based methods have proven effective in the process of optimizing network reconfiguration with DG presence. The proposed and other methods were tested on the distribution network of the IEEE standard 69-bus system. The results show that simultaneous network reconfiguration and DG installation methods are more effective in reducing power loss and increasing voltage profiles compared to other methods. The effect of the number of DG installation locations on the reduction in power is studied at different load levels. The results show that the percentage power loss reduction increases because the number of DG installation locations increases from one to four, but the rate of increase decreases when the location is increased from one to four at all load levels.

\section{Appendix}

Table A.1. Load data of distribution network under study

\begin{tabular}{|c|c|c|c|c|c|}
\hline $\begin{array}{c}\text { Bus } \\
\text { Number }\end{array}$ & $\begin{array}{c}\mathrm{PL}_{\mathrm{L}} \\
(\mathrm{kW})\end{array}$ & $\begin{array}{c}\mathrm{Q}_{\mathrm{L}} \\
(\mathrm{kVAr})\end{array}$ & $\begin{array}{c}\text { Bus } \\
\text { Number }\end{array}$ & $\begin{array}{c}\mathrm{PL}_{\mathrm{L}} \\
(\mathrm{kW})\end{array}$ & $\begin{array}{c}\mathrm{Q}_{\mathrm{L}} \\
(\mathrm{kVAr})\end{array}$ \\
\hline 6 & 2.60 & 2.20 & 37 & 26.00 & 18.55 \\
\hline 7 & 40.40 & 30.00 & 39 & 24.00 & 17.00 \\
\hline 8 & 75.00 & 54.00 & 40 & 24.00 & 17.00 \\
\hline 9 & 30.00 & 22.00 & 41 & 1.20 & 1.00 \\
\hline 10 & 28.00 & 19.00 & 43 & 6.00 & 4.30 \\
\hline 11 & 145.00 & 104.00 & 45 & 39.22 & 26.30 \\
\hline 12 & 145.00 & 104.00 & 46 & 39.22 & 26.30 \\
\hline 13 & 8.00 & 5.00 & 48 & 79.00 & 56.40 \\
\hline 14 & 8.00 & 5.50 & 49 & 384.70 & 274.50 \\
\hline 16 & 45.50 & 30.00 & 50 & 384.70 & 274.50 \\
\hline 17 & 60.00 & 35.00 & 51 & 40.50 & 28.30 \\
\hline 18 & 60.00 & 35.00 & 52 & 3.60 & 2.70 \\
\hline 20 & 1.00 & 0.60 & 53 & 4.35 & 3.50 \\
\hline 21 & 114.00 & 81.00 & 54 & 26.40 & 19.00 \\
\hline 22 & 5.00 & 3.50 & 55 & 24.00 & 17.20 \\
\hline 24 & 28.00 & 20.00 & 59 & 100.00 & 72.00 \\
\hline
\end{tabular}

\begin{tabular}{|c|c|c|c|c|c|}
\hline 26 & 14.00 & 10.00 & 61 & $1,244.00$ & 888.00 \\
\hline 27 & 14.00 & 10.00 & 62 & 32.00 & 23.00 \\
\hline 28 & 26.00 & 18.60 & 64 & 227.00 & 162.00 \\
\hline 29 & 26.00 & 18.60 & 65 & 59.00 & 42.00 \\
\hline 33 & 14.00 & 10.00 & 66 & 18.00 & 13.00 \\
\hline 34 & 19.50 & 14.00 & 67 & 18.00 & 13.00 \\
\hline 35 & 6.00 & 4.00 & 68 & 28.00 & 20.00 \\
\hline 36 & 26.00 & 18.55 & 69 & 28.00 & 20.00 \\
\hline
\end{tabular}

Table A.2. Branch data of distribution network under study

\begin{tabular}{|c|c|c|c|c|}
\hline $\begin{array}{l}\text { Branch } \\
\text { Number }\end{array}$ & $\begin{array}{l}\text { Sending } \\
\text { end bus }\end{array}$ & $\begin{array}{c}\text { Receiving } \\
\text { end bus }\end{array}$ & $\begin{array}{c}\mathrm{R} \\
(\Omega)\end{array}$ & $\begin{array}{c}X \\
(\Omega)\end{array}$ \\
\hline 1 & 1 & 2 & 0.0005 & 0.0012 \\
\hline 2 & 2 & 3 & 0.0005 & 0.0012 \\
\hline 3 & 3 & 4 & 0.0015 & 0.0036 \\
\hline 4 & 4 & 5 & 0.0251 & 0.0294 \\
\hline 5 & 5 & 6 & 0.3660 & 0.1864 \\
\hline 6 & 6 & 7 & 0.3811 & 0.1941 \\
\hline 7 & 7 & 8 & 0.0922 & 0.0470 \\
\hline 8 & 8 & 9 & 0.0493 & 0.0251 \\
\hline 9 & 9 & 10 & 0.8190 & 0.2707 \\
\hline 10 & 10 & 11 & 0.1872 & 0.0619 \\
\hline 11 & 11 & 12 & 0.7114 & 0.2351 \\
\hline 12 & 12 & 13 & 1.0300 & 0.3400 \\
\hline 13 & 13 & 14 & 1.0440 & 0.3450 \\
\hline 14 & 14 & 15 & 1.0580 & 0.3496 \\
\hline 15 & 15 & 16 & 0.1966 & 0.0650 \\
\hline 16 & 16 & 17 & 0.3744 & 0.1238 \\
\hline 17 & 17 & 18 & 0.0047 & 0.0016 \\
\hline 18 & 18 & 19 & 0.3276 & 0.1083 \\
\hline 19 & 19 & 20 & 0.2106 & 0.0690 \\
\hline 20 & 20 & 21 & 0.3416 & 0.1129 \\
\hline 21 & 21 & 22 & 0.0140 & 0.0046 \\
\hline 22 & 22 & 23 & 0.1591 & 0.0526 \\
\hline 23 & 23 & 24 & 0.3463 & 0.1145 \\
\hline 24 & 24 & 25 & 0.7488 & 0.2475 \\
\hline 25 & 25 & 26 & 0.3089 & 0.1021 \\
\hline 26 & 26 & 27 & 0.1732 & 0.0572 \\
\hline 27 & 3 & 28 & 0.0044 & 0.0108 \\
\hline 28 & 28 & 29 & 0.0640 & 0.1565 \\
\hline 29 & 29 & 30 & 0.3978 & 0.1315 \\
\hline 30 & 30 & 31 & 0.0702 & 0.0232 \\
\hline 31 & 31 & 32 & 0.3510 & 0.1160 \\
\hline 32 & 32 & 33 & 0.8390 & 0.2816 \\
\hline 33 & 33 & 34 & 1.7080 & 0.5646 \\
\hline 34 & 34 & 35 & 1.4740 & 0.4873 \\
\hline 35 & 3 & 36 & 0.0044 & 0.0108 \\
\hline 36 & 36 & 37 & 0.0640 & 0.1565 \\
\hline
\end{tabular}




\begin{tabular}{|c|c|c|c|c|}
\hline 37 & 37 & 38 & 0.1053 & 0.1230 \\
\hline 38 & 38 & 39 & 0.0304 & 0.0355 \\
\hline 39 & 39 & 40 & 0.0018 & 0.0021 \\
\hline 40 & 40 & 41 & 0.7283 & 0.8509 \\
\hline 41 & 41 & 42 & 0.3100 & 0.3623 \\
\hline 42 & 42 & 43 & 0.0410 & 0.0478 \\
\hline 43 & 43 & 44 & 0.0092 & 0.0116 \\
\hline 44 & 44 & 45 & 0.1089 & 0.1373 \\
\hline 45 & 45 & 46 & 0.0009 & 0.0012 \\
\hline 46 & 4 & 47 & 0.0034 & 0.0084 \\
\hline 47 & 47 & 48 & 0.0851 & 0.2083 \\
\hline 48 & 48 & 49 & 0.2898 & 0.7091 \\
\hline 49 & 49 & 50 & 0.0822 & 0.2011 \\
\hline 50 & 8 & 51 & 0.0928 & 0.0473 \\
\hline 51 & 51 & 52 & 0.3319 & 0.1114 \\
\hline 52 & 9 & 53 & 0.1740 & 0.0886 \\
\hline 53 & 53 & 54 & 0.2030 & 0.1034 \\
\hline 54 & 54 & 55 & 0.2842 & 0.1447 \\
\hline 55 & 55 & 56 & 0.2813 & 0.1433 \\
\hline 56 & 56 & 57 & 1.5900 & 0.5337 \\
\hline 57 & 57 & 58 & 0.7837 & 0.2630 \\
\hline 58 & 58 & 59 & 0.3042 & 0.1006 \\
\hline 59 & 59 & 60 & 0.3861 & 0.1172 \\
\hline 60 & 60 & 61 & 0.5075 & 0.2585 \\
\hline 61 & 61 & 62 & 0.0974 & 0.0496 \\
\hline 62 & 62 & 63 & 0.1450 & 0.0738 \\
\hline 63 & 63 & 64 & 0.7105 & 0.3619 \\
\hline 64 & 64 & 65 & 1.0410 & 0.5302 \\
\hline 65 & 11 & 66 & 0.2012 & 0.0611 \\
\hline 66 & 66 & 67 & 0.0047 & 0.0014 \\
\hline 67 & 12 & 68 & 0.7394 & 0.2444 \\
\hline 68 & 68 & 69 & 0.0047 & 0.0016 \\
\hline \multicolumn{5}{|c|}{ Tie line } \\
\hline 69 & 11 & 43 & 0.5000 & 0.5000 \\
\hline 70 & 13 & 21 & 0.5000 & 0.5000 \\
\hline 71 & 15 & 46 & 1.0000 & 0.5000 \\
\hline 72 & 50 & 59 & 2.0000 & 1.0000 \\
\hline 73 & 27 & 65 & 1.0000 & 0.5000 \\
\hline
\end{tabular}

\section{Acknowledgements}

This work was supported by Universitas Muhammadiyah Yogyakarta.

\section{References}

[1] Syahputra, R., Soesanti, I., Ashari, M. (2016). Performance Enhancement of Distribution Network with DG Integration Using Modified PSO Algorithm. Journal of Electrical Systems (JES), 12(1), pp. 1-19.
[2] Syahputra, R., Robandi, I., Ashari, M. (2014). "Optimal Distribution Network Reconfiguration with Penetration of Distributed Energy Resources", Proceeding of 2014 1st International Conference on Information Technology, Computer, and Electrical Engineering (ICITACEE) 2014, UNDIP Semarang, pp. 388 - 393.

[3] Syahputra, R., (2012), "Fuzzy Multi-Objective Approach for the Improvement of Distribution Network Efficiency by Considering DG", International Journal of Computer Science \& Information Technology (IJCSIT), Vol. 4, No. 2, pp. 57-68.

[4] Syahputra, R., (2012), "Distributed Generation: State of the Arts dalam Penyediaan Energi Listrik", LP3M UMY, Yogyakarta, 2012.

[5] Syahputra, R., (2016), "Transmisi dan Distribusi Tenaga Listrik”, LP3M UMY, Yogyakarta, 2016.

[6] Syahputra, R., Robandi, I., Ashari, M. (2014). Optimization of Distribution Network Configuration with Integration of Distributed Energy Resources Using Extended Fuzzy Multi-objective Method. International Review of Electrical Engineering (IREE), 9(3), pp. 629-639.

[7] Syahputra, R. (2016). Application of Neuro-Fuzzy Method for Prediction of Vehicle Fuel Consumption. Journal of Theoretical and Applied Information Technology (JATIT), 86(1), pp. 138-149.

[8] Syahputra, R., Robandi, I., Ashari, M. (2015). Performance Improvement of Radial Distribution Network with Distributed Generation Integration Using Extended Particle Swarm Optimization Algorithm. International Review of Electrical Engineering (IREE), 10(2). pp. 293-304.

[9] Syahputra, R., Robandi, I., Ashari, M. (2015). Reconfiguration of Distribution Network with DER Integration Using PSO Algorithm. TELKOMNIKA, 13(3). pp. 759-766.

[10] Syahputra, R., Robandi, I., Ashari, M. (2015). PSO Based Multi-objective Optimization for Reconfiguration of Radial Distribution Network. International Journal of Applied Engineering Research (IJAER), 10(6), pp. 14573-14586.

[11] Syahputra, R., Robandi, I., Ashari, M., (2012), "Reconfiguration of Distribution Network with DG Using Fuzzy Multi-objective Method", International Conference on Innovation, Management and Technology Research (ICIMTR), May 21-22, 2012, Melacca, Malaysia.

[12] Jamal, A., Syahputra, R. (2012), “Adaptive NeuroFuzzy Approach for the Power System Stabilizer Model in Multi-machine Power System", International Journal of Electrical \& Computer Sciences (IJECS), Vol. 12, No. 2, 2012.

[13] Syahputra, R., Soesanti, I. (2016). Application of Green Energy for Batik Production Process. Journal of Theoretical and Applied Information Technology (JATIT), 91(2), pp. 249-256. 
[14] Syahputra, R., Robandi, I., Ashari, M. (2014). Performance Analysis of Wind Turbine as a Distributed Generation Unit in Distribution System. International Journal of Computer Science \& Information Technology (IJCSIT), Vol. 6, No. 3, pp. $39-56$

[15] Jamal, A., Suripto, S., Syahputra, R. (2015). MultiBand Power System Stabilizer Model for Power Flow Optimization in Order to Improve Power System Stability. Journal of Theoretical and Applied Information Technology, 80(1), pp. 116-123.

[16] Syahputra, R., Soesanti, I. (2016). An Optimal Tuning of PSS Using AIS Algorithm for Damping Oscillation of Multi-machine Power System. Journal of Theoretical and Applied Information Technology (JATIT), 94(2), pp. 312-326.

[17] Soesanti, I., Syahputra, R. (2016). Batik Production Process Optimization Using Particle Swarm Optimization Method. Journal of Theoretical and Applied Information Technology (JATIT), 86(2), pp. 272-278.

[18] Jamal, A., Syahputra, R. (2016). Heat Exchanger Control Based on Artificial Intelligence Approach. International Journal of Applied Engineering Research (IJAER), 11(16), pp. 9063-9069.

[19] Syahputra, R. (2015). Characteristic Test of Current Transformer Based EMTP Shoftware. Jurnal Teknik Elektro, 1(1), pp. 11-15.

[20] Syahputra, R., Soesanti, I. (2015). Power System Stabilizer model based on Fuzzy-PSO for improving power system stability. 2015 International Conference on Advanced Mechatronics, Intelligent Manufacture, and Industrial Automation (ICAMIMIA), Surabaya, 15-17 Oct. 2015 pp. 121 126.

[21] Syahputra, R., Robandi, I., Ashari, M., (2013), "Distribution Network Efficiency Improvement Based on Fuzzy Multi-objective Method". International Seminar on Applied Technology, Science and Arts (APTECS). 2013; pp. 224-229.

[22] Syahputra, R., Soesanti, I. (2015). "Control of Synchronous Generator in Wind Power Systems Using Neuro-Fuzzy Approach", Proceeding of International Conference on Vocational Education and Electrical Engineering (ICVEE) 2015, UNESA Surabaya, pp. 187-193.

[23] Syahputra, R., (2013), “A Neuro-Fuzzy Approach For the Fault Location Estimation of Unsynchronized Two-Terminal Transmission Lines", International Journal of Computer Science \& Information Technology (IJCSIT), Vol. 5, No. 1, pp. 23-37.

[24] Jamal, A., Syahputra, R. (2013). UPFC Based on Adaptive Neuro-Fuzzy for Power Flow Control of Multimachine Power Systems. International Journal of Engineering Science Invention (IJESI), 2(10), pp. 05-14.
[25] Syahputra, R. (2010). Fault Distance Estimation of Two-Terminal Transmission Lines. Proceedings of International Seminar on Applied Technology, Science, and Arts (2nd APTECS), Surabaya, 21-22 Dec. 2010, pp. 419-423.

[26] Syahputra, R., Soesanti, I. (2016). DFIG Control Scheme of Wind Power Using ANFIS Method in Electrical Power Grid System. International Journal of Applied Engineering Research (IJAER), 11(7), pp. 5256-5262.

[27] Jamal, A., Suripto, S., Syahputra, R. (2016). Performance Evaluation of Wind Turbine with Doubly-Fed Induction Generator. International Journal of Applied Engineering Research (IJAER), 11(7), pp. 4999-5004.

[28] Syahputra, R., Soesanti, I. (2016). Design of Automatic Electric Batik Stove for Batik Industry. Journal of Theoretical and Applied Information Technology (JATIT), 87(1), pp. 167-175.

[29] Jamal, A., Syahputra, R. (2014). Power Flow Control of Power Systems Using UPFC Based on Adaptive Neuro Fuzzy. IPTEK Journal of Proceedings Series. 2014; 1(1): pp. 218-223.

[30] Syahputra, R., Soesanti, I. (2016). Power System Stabilizer Model Using Artificial Immune System for Power System Controlling. International Journal of Applied Engineering Research (IJAER), 11(18), pp. 9269-9278.

[31] Syahputra, R., (2014), "Estimasi Lokasi Gangguan Hubung Singkat pada Saluran Transmisi Tenaga Listrik", Jurnal Ilmiah Semesta Teknika Vol. 17, No. 2, pp. 106-115, Nov 2014.

[32] Jamal, A., Syahputra, R., (2011), "Design of Power System Stabilizer Based on Adaptive Neuro-Fuzzy Method". International Seminar on Applied Technology, Science and Arts (APTECS). 2011; pp. 14-21.

\section{Authors' information}

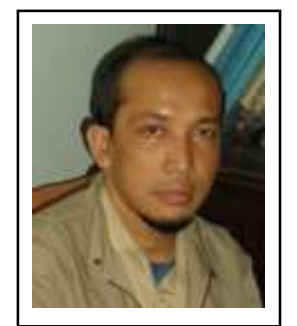

Ramadoni Syahputra received B.Sc. degree from Institut Teknologi Medan in 1998, M.Eng. degree from Department of Electrical Engineering, Universitas Gadjah Mada, Yogyakarta, Indonesia in 2002, and Ph.D degree at the Department of Electrical Engineering, Faculty of Industrial Technology, Institut Teknologi Sepuluh Nopember, Surabaya, Indonesia in 2015. Dr. Ramadoni Syahputra is a Lecturer in Department of Electrical Engineering, Faculty of Engineering, Universitas Muhammadiyah Yogyakarta, Indonesia. His research interests are in computational of power system, artificial intelligence in power system, power system control, the application of fuzzy logic in power system, optimization, distributed energy resources, and renewable energy. 